\title{
Affective Priming with Pictures of Emotional Scenes: The Role of Perceptual Similarity and Category Relatedness
}

\author{
Pedro Avero and Manuel G. Calvo \\ Universidad de La Laguna
}

Prime pictures portraying pleasant or unpleasant scenes were briefly presented (150-ms display; SOAs of 300 or $800 \mathrm{~ms}$ ), followed by probe pictures either congruent or incongruent in emotional valence. In an evaluative decision task, participants responded whether the probe was emotionally positive or negative. Affective priming was reflected in shorter response latencies for congruent than for incongruent prime-probe pairs. Although this effect was enhanced by perceptual similarity between the prime and the probe, it also occurred for probes that were physically different, and the effect generalized across semantic categories (animals vs. people). It is concluded that affective priming is a genuine phenomenon, in that it occurs as a function of stimulus emotional content, in the absence of both perceptual similarity and semantic category relatedness between the prime and the probe.

Keywords: affective, priming, pictures, emotional processing, perception

En un paradigma de activación o priming afectivo, se presentaron pares de fotografías: primero una como activadora (prime), brevemente (exposición de $150 \mathrm{~ms}$; SOAs de 300 u $800 \mathrm{~ms}$ ), y a continuación otra como prueba (probe). Las dos fotografías podían ser congruentes o incongruentes en valencia emocional (agradables vs. desagradables). Los participantes tenían que responder si la foto de prueba era emocionalmente positiva o negativa. Se observó un efecto de priming afectivo al producirse latencias de respuesta más cortas cuando la foto de prueba era congruente en valencia con la foto activadora que cuando eran incongruentes. Aunque este efecto se incrementó en función de la semejanza física entre los estímulos de cada par, ocurrió también cuando éstos eran físicamente diferentes. Además, dicho efecto se generalizó a categorías semánticas distintas (escenas de animales vs. de personas). Se concluye que el fenómeno de procesamiento afectivo temprano es genuino, que ocurre en función del contenido emocional de los estímulos, y en ausencia de semejanza perceptual y de relación semántica entre el estímulo activador y el de prueba.

Palabras clave: afectivo, activación, fotografías, procesamiento emocional, percepción

This research was supported by Grant SEJ2004-420/PSIC, from the Ministerio de Educación y Ciencia.

Address correspondence to: Pedro Avero, Departamento de Personalidad, Evaluación y Tratamientos Psicológicos, Universidad de La Laguna, 38205 Tenerife (Spain). Fax: + 34922317 461. E-mail: paverode@ull.es 
Affective priming involves facilitation of responses to a probe stimulus following a prime stimulus when both have the same emotional valence (e.g., pleasant-pleasant), in comparison with when the prime and the probe differ in valence (e.g., pleasant-unpleasant). This is a variant of the more general phenomenon of cognitive priming, in which the speed or accuracy of a decision to a target is increased when a previous stimulus is related in meaning or form (e.g., Neely, 1991). Affective priming has been investigated by means of the affective priming paradigm (see reviews in Fazio, 2001, and Klauer \& Musch, 2003). In a typical study, an emotionally positive or negative prime word or picture is followed by a positive or negative probe word or picture on each trial. Participants are asked to decide whether the probe is positive or negative in emotional valence, to classify it into an emotional category, or just to name it. Evidence of priming has been frequently found for both words and pictures, especially when the affective evaluation task (i.e., affective decision) has been used. As priming has appeared following brief presentations of the prime (typically, around $200 \mathrm{~ms}$ ), the effect is thought to reflect automatic processing of emotional valence.

Prior research has examined the affective priming of emotional pictures by means of two complementary approaches. First, pictures have served both as primes and probes (Carroll \& Young, 2005: Experiment 2; Hermans, De Houwer, \& Eelen, 1994: Experiment 1; Hermans, Spruyt, De Houwer, \& Eelen, 2003: Experiment 1; Hietanen \& Korpela, 2004; Spruyt, Hermans, De Houwer, \& Eelen, 2002: Experiments 1, 2 and 3; Spruyt, Hermans, De Houwer, \& Eelen, 2004; Storbeck \& Robinson, 2004: Experiment 5). Second, pictures have been used as primes and printed words (or vocal expressions; Korpela, Klemettilä, \& Hietanen, 2002) as probes (Banse, 2001: Experiments 1 and 2; Carroll \& Young, 2005: Experiments 1 and 4; Giner-Sorolla, García, \& Bargh, 1999: Experiments 1 and 2; Hermans, Baeyens, Lamote, Spruyt, \& Eelen, 2005; Hermans, Spruyt, De Houwer, et al., 2003: Experiments 2 and 3; Hermans, Spruyt, \& Eelen, 2003; Hermans, Vansteenwegen, Crombez, Baeyens, \& Eelen, 2002; Spruyt et al., 2002: Experiment 3; Storbeck \& Robinson, 2004: Experiment 4). In spite of the considerable methodological variability across these studies (e.g., the nature of prime and probe stimuli: e.g., scenes vs. facial expressions vs. objects; or the probe task: naming vs. evaluative decision vs. emotion classification), generally facilitation has been found in the processing of congruent (or related) versus incongruent (or unrelated) prime-probe sequences, with the notable exception of Storbeck and Robinson (2004). This makes affective priming with pictures as primes a relatively robust phenomenon.

The present study attempts to make a contribution to prior research on affective priming with pictures by investigating the nature of the representation that is extracted from the prime stimulus. More specifically, we aim to determine whether genuine affective content is automatically obtained from the prime, and whether it is this affective content that determines the facilitation of the response to the probe. Storbeck and Robinson (2004) have pointed out that there are nonaffective processes, such as perceptual identification and semantic categorization, that can also occur automatically and that might be involved in the effects attributed to affective priming. It is, therefore, important to separate the relative contribution of three dimensions: affective, semantic, and perceptual. In this context, our approach is relevant to two important issues. First, whether processing of emotional content per se is responsible for the observed affective priming effects, or whether these could be due to the physical similarity or semantic category relatedness between primes and probes, that is, the possibility of a greater similarity or relatedness between primes and probes of the same emotional valence than between primes and probes of different valence. And, second, this is relevant to the issue of whether affective processing occurs earlier, in parallel to, or follows perceptual and semantic processing. Recent views of emotional processing (Cave \& Batty, in press; Storbeck, Robinson, \& McCourt, in press) have challenged the primacyof-affect idea (Bargh, 1997; Zajonc, 2000). According to these views, objects must first be identified perceptually and semantically before their affective content can be extracted. This implies that affective processing starts later and is dependent on perceptual and semantic processing.

The issue of the role of prime-probe perceptual similarity in affective priming has not been directly addressed in prior research. In most studies, a limited number of different primes and probes have been used (generally, 16 or fewer different pictures of positive and of negative valence; e.g., Carroll \& Young, 2005; Hietanen \& Korpela, 2004; Spruyt et al., 2002) in repeated trials. To examine this issue, an ideal condition would require a great deal of variation in the physical appearance of primes and probes, and no repetition. In the current experiments, we have used 32 pleasant and 32 unpleasant different pictures, and they were presented only once as primes and probes, to avoid pre-exposure and practice effects. Furthermore, a specific approach to determine the extent to which affective priming depends on physical appearance would involve manipulation of the degree of perceptual similarity within and across emotional valence. Some prior studies have provided support to the idea that physical similarity between the prime and the probe is not required, as priming has appeared when the primes were pictures and the probes were words (hence, physically different; e.g., Carroll \& Young, 2005; Hermans, Spruyt, \& Eelen, 2003). In an alternative approach, with pictorial stimuli as both primes and probes, we have addressed this first issue in Experiment 1, in which the perceptual similarity (identical vs. reversed vs. different) of affectively congruent and incongruent prime-probe sequences was varied. Affective priming was predicted to survive differences in physical appearance between the prime and the probe, although priming should be enhanced by the degree of perceptual similarity. This would reveal that the affective content of the prime is processed, but that emotional processing does not 
precede perceptual processing. See more specific predictions and arguments in the introduction to Experiment 1.

Regarding the issue of the role of prime-probe semantic category relatedness in affective priming, prior research has provided inconclusive results. Storbeck and Robinson (2004) found semantic category priming, but not affective priming. More specifically, two types of valenced pictures of animals of different semantic categories were presented (pleasant: rabbit, puppy, swan, and sparrow; and unpleasant: snake, spider, porcupine, and raven). There were priming effects when the probes matched the primes in both valence and category, but not when there was only valence matching. According to the authors, these findings are inconsistent with the idea that emotional processing (i.e., valence distinctions) is performed before a relatively refined semantic analysis. In contrast, other studies suggest that an affective representation is obtained from the prime and then determines affective priming on semantically different probes. This can be inferred from recent experiments (Carroll \& Young, 2005, Experiment 2 ) in which there was priming as a function of prime-probe congruence in emotional valence, even though the primes and the probes were categorically different (i.e., primes: scenes depicting people and animals; and probes: human facial expressions of emotion). Nevertheless, the relative contribution of semantic category processing and affective processing cannot be totally separated in the Carroll and Young study. The reason is that the valence and the semantic category of the primes were not orthogonally combined. In order to determine whether there is affective priming across different semantic categories, in our Experiment 2, we combined the semantic category (people vs. animals) and valence (pleasant vs. unpleasant) of the primes. If affective content is extracted from the primes, it should influence evaluative decisions on the affectively congruent probes, regardless of differences between the prime and the probe in specific semantic content and category. See more specific predictions and arguments in the introduction to Experiment 2.

\section{Experiment 1}

Unpleasant or pleasant prime pictures were presented for $150 \mathrm{~ms}$, followed by congruent or incongruent probes, in a 300- or an 800-ms stimulus onset asynchrony (SOA). The 150-ms prime exposure was chosen, rather than the more usual 200-ms display (e.g., Hermans, Spruyt, \& Eelen, 2003) because minimal saccade latency is $150 \mathrm{~ms}$ (see Rayner, 1998). This implies that viewing of the prime stimulus in the current study was restricted to a single eye fixation. Participants performed an affective decision task on the probe, by responding whether it was positive or negative. The difference in response latencies between congruent and incongruent probes was used as an index of affective priming. If the affective content of the prime is processed, then correct evaluative decisions on the probe will be faster when the prime and the probe are congruent than when these are incongruent in emotional valence.

The specific aim of Experiment 1 was to assess the degree to which affective priming depends on physical similarity between the prime and the probe. This is relevant to the issue of the extent to which affective processing precedes, is parallel, or follows perceptual identification of the prime. To address this issue, the physical similarity (identical vs. reversed in left-right orientation vs. different) between primes and probes was varied, while the emotional valence was constant. It should, nevertheless, be noted that affective congruence and perceptual similarity were not orthogonally combined, due to the impossibility of producing a prime and a probe that are incongruent affectively while being physically identical or reversed. Accordingly, affective congruence versus incongruence was manipulated only for the physically different condition. If affective processing is independent from, or precedes, perceptual identification, then not only will affective priming emerge when the congruent prime and probe are physically different, but also affective priming will be similar in the different and the reversed, and possibly the identical, conditions. In contrast, to the extent that affective priming increases as a function of physical similarity, this would reveal that emotional processing depends on perceptual identification.

\section{Method}

\section{Participants}

Forty-eight psychology undergraduates (37 females; 11 males) at La Laguna University participated for course credit.

\section{Stimuli}

Sixty-four different experimental pictures were presented, which portrayed people either in unpleasant (32) or pleasant (32) scenes. All the pictures were presented either in their original spatial orientation or horizontally reversed, as a mirror image, in different combinations (see Design). The original pictures were selected from the International Affective Picture System (IAPS; Center for the Study of Emotion and Attention, 1999). The IAPS numbers are indicated in the Appendix. The mean IAPS valence scores of the selected stimuli in undergraduate Spanish samples (Moltó et al., 1999; Vila et al., 2001) are 2.32 (unpleasant) and 7.71 (pleasant), on a 9-point scale, $t(62)=35.18, p<.0001$.

Both in Experiment 1 and 2, each picture was presented only once as a prime and once as a probe to each participant, to avoid practice effects. Each picture subtended a visual angle of $12.1^{\circ}$ (width: $11.7 \mathrm{~cm}$ ) by $10.1^{\circ}$ (height: $9.7 \mathrm{~cm}$ ), at a 55 $\mathrm{cm}$ viewing distance. Participants had their head positioned on a chin and forehead rest. All pictures were presented in their original colors against a dark background. The pictures were displayed on a SVGA 17" monitor with a 100-Hz refresh 
rate, at a resolution of $800 \times 600$ pixels, connected to a Pentium-IV computer. The E-Prime experimental software (Schneider, Eschman, \& Zuccolotto, 2002) controlled stimulus presentation and response collection. Response accuracy and latency were collected through key presses on specified keys. For half of the participants in each experimental condition, the "positive" response key was D and the "negative" key was $\mathrm{L}$, in a standard computer keyboard, whereas the reverse applied to the other half of the participants.

\section{Procedure}

The participants were informed that they would be presented with a sequence of two photographs on each trial, in the center of the screen, that their task was to respond as soon as possible whether the second photograph was positive or negative in emotional valence, and that both accuracy and reaction times would be collected. No mention was made of the relationship between the first (prime) and the second (probe) picture, and participants were not asked to attend or to ignore the prime. They were simply told that the prime would appear very quickly and that nothing had to be done about it. A trial started with a central cross as a fixation point for $500 \mathrm{~ms}$, followed by the prime stimulus for $150 \mathrm{~ms}$, a blank 150- or 650 -ms interval (hence SOAs of 300 or $800 \mathrm{~ms}$ ), and the probe stimulus, which remained on the screen until the participant responded or for 2 seconds. The inter-trial interval was $3 \mathrm{~s}$.

\section{Design}

A mixed factorial design involved the combination of two within-subjects factors: prime-probe relatedness (identical vs. reversed vs. congruent vs. incongruent), and valence of the probe (unpleasant vs. pleasant); with a between-subjects factor: SOA (300 vs. $800 \mathrm{~ms}$ ). At each SOA, for the 32 pleasant-people probes, each participant was presented with 8 identical primes, 8 reversed primes, 8 pleasant (but different in form) primes, and 8 unpleasant (and different in form) primes; the same applied to the 32 unpleasant-people probes. In the identical condition, the prime and the probe stimulus were exactly the same in all respects. In the reversed condition, the horizontal orientation of the prime picture was mirror-reversed from left to right with respect to the same probe picture. There were 24 participants at each SOA level. All trials were presented in random order for each participant.

\section{Results and Discussion}

Both for Experiments 1 and 2, reaction times in the valence evaluation task that were above $1,500 \mathrm{~ms}$ or below $300 \mathrm{~ms}$ were removed (1.3\%), to deal with outliers. In addition, reaction times that were 2.5 standard deviations $(S D)$ above or below the mean were replaced by the $\pm 2.5 S D$ values in each experiment, separately. This represented $2.8 \%$ of cases across experiments. Analyses of variance were conducted for accuracy and reaction times for correct responses. Accuracy was high in all the experiments (3.8\% total errors and misses) and did not differ across conditions (or experiments). Accordingly, subsequent analyses were conducted only on the correct reaction times. The alpha level was set at .05 for all analyses. Unless otherwise indicated, nonsignificant effects will not be reported.

The 2 (valence of probe) $\times 4$ (prime-probe relatedness) $\times$ 2 (SOA) ANOVA revealed a strong effect of relatedness, $F$ (3, $138)=42.60, p<.0001, \eta_{\mathrm{p}}^{2}=.48$. Post hoc multiple comparisons, with alpha level adjusted by Bonferroni corrections, showed significant differences $(p s<.01)$ between all relatedness levels: identical $(M=608 \mathrm{~ms} ; S D=138)$, reversed $(M=663 \mathrm{~ms} ; S D=150)$, congruent $(M=739 \mathrm{~ms}$; $S D=174)$, and incongruent $M=793 \mathrm{~ms} ; S D=181)$. There was also a borderline relatedness by SOA interaction, $F(3$, $138)=2.70, p=.05, \eta_{\mathrm{p}}{ }^{2}=.16$ (see Figure 1). To decompose this interaction, simple effect tests were performed for each SOA condition. In the 300-ms SOA condition, there was a main effect of relatedness, $F(3,69)=25.85, p<.0001, \eta_{\mathrm{p}}{ }^{2}$ $=.53$, with significant differences between all levels in post hoc comparisons $(p s<.05)$. In the $800-\mathrm{ms}$ SOA condition, there was also a main effect of relatedness, $F(3,69)=17.57$, $p<.0001, \eta_{\mathrm{p}}{ }^{2}=.43$. However, in this case, post hoc comparisons revealed significant differences (all $p s<.05$ ) only between the two physically related conditions (i.e., identical and reversed) and the two physically different conditions (i.e., congruent and incongruent), with no significant differences between the identical and the reversed probes, or between the congruent and the incongruent probes. Accordingly, both for affective congruence and for physical relatedness, the effects decreased at the longer SOA, in comparison with the shorter SOA. This tendency was further examined in Experiment 2, by combining the results of both experiments for the conditions of most interest, that is, congruent and incongruent.

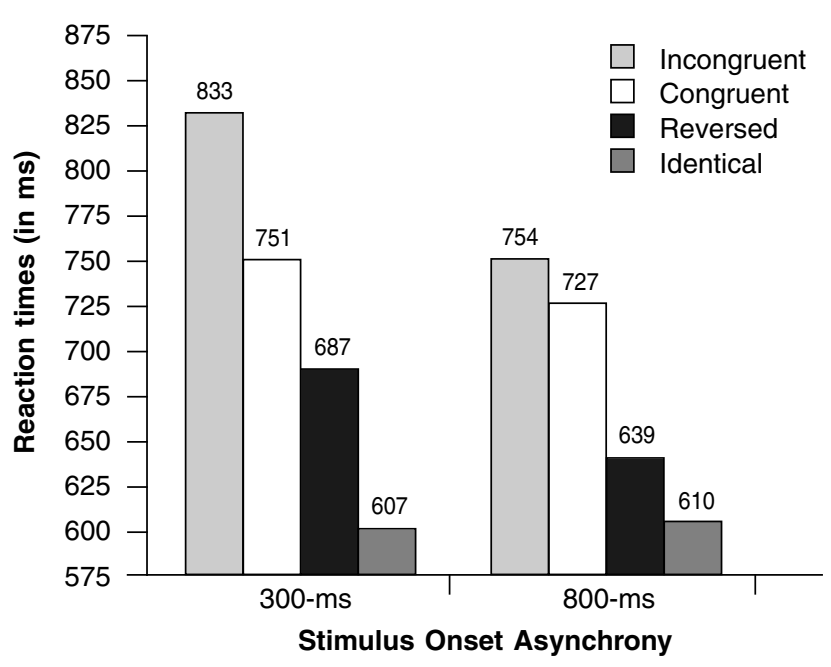

Figure 1. Mean reaction times as a function of affective primeprobe congruence and physical prime-probe relatedness, and SOA (Experiment 1). 
Correct responses were faster when probes were congruent with primes in emotional valence than when they were incongruent. This is consistent with most prior studies using pictorial stimuli (e.g., Carroll \& Young, 2005; Hermans et al., 1994; Hietanen \& Korpela, 2004; Spruyt et al., 2002), and suggests that affective content is extracted from the prime and that this content determines the observed priming effects. The specific finding of this experiment reveals that perceptual processing precedes affective processing. This is inferred from the fact that reaction times on the affective evaluation task were shorter as physical similarity increased between the prime and the probe. That is, affective priming progressively increased from the different versus reversed versus identical prime-probe pairs, even though there was equivalent congruence in affective valence in all three conditions. However, although physical similarity enhances affective priming (i.e., identical vs. reversed, where affective content was exactly the same), physical similarity is not necessary for affective priming. This is inferred from the fact that affective priming occurred even when primes and probes were physically different, provided that they were congruent in affect (i.e., congruent vs. incongruent condition). Finally, it is interesting to note that the effect of valence was not significant, nor did congruence interact with valence, which reveals that affective priming is equivalent for both pleasant and unpleasant stimuli.

The results of Experiment 1 have shown that affective priming occurs to a significant extent as a function of congruence in affective content, although it is enhanced by physical similarity. There is, however, the question of the contribution of semantic relatedness. According to Storbeck and Robinson (2004), there is the possibility of a confound of affective with nonaffective priming due to semantic category relatedness between primes and probes. This issue is relevant here because in Experiment 1, both the primes and the probes always belonged to the same category (i.e., people). This potential confound also applies to some of the picture-word studies (e.g., Carroll \& Young, 2005, Experiments 1 and 4), in which the prime and the probe, though physically different, generally represented the same object, and so there was semantic relatedness. Accordingly, it is possible that the prime stimulus primed the congruent probe stimulus because of semantic category relatedness, rather than because of affective congruence. To address this issue, we conducted Experiment 2, in which the priming effects of pictures of two different categories, i.e., animals and people, were compared.

\section{Experiment 2}

Primes and probes were combined across stimulus category (pictures of people and animals, instead of only people), to examine generalization effects. If affective content is extracted from an emotional prime (and not only semantic category information) then this will facilitate processing of an emotionally congruent probe, regardless of semantic category. That is, animal and people prime pictures are expected to prime affective responses on people probe pictures similarly, provided that primes and probes share the same affective valence. Alternatively, if semantic and affective priming interact, the amount of priming will be greater when the primes and the probes match in both category membership and affective valence (e.g., both pleasant people or both unpleasant people) than when they match only in valence (e.g., pleasant animal and pleasant people).

\section{Method}

\section{Participants}

Forty-eight psychology undergraduates (38 females, 10 males) at La Laguna University participated for course credit. The samples of participants were different for Experiments 1 and 2, although they were drawn from the same pool of first-year students (ranging in age from 19 to $22 ; M=19.9$ ), and were assigned randomly, in order to make comparisons across the experiments.

\section{Stimuli}

Eighty pictures were presented. They were either unpleasant (32 portrayed people, 8 portrayed animals) or pleasant (32, people; 8 , animals). In addition to those used in Experiment 1, 16 new photographs of animals were used, 14 of which were obtained from the IAPS (see the Appendix). For the animal pictures, the mean valence scores were 3.38 (unpleasant) and 7.95 (pleasant), on a 9-point scale, $t(14)=38.70, p<.0001$.

\section{Apparatus, Procedure, and Design}

These were the same as in Experiment 1, except for the design. Prime category (people vs. animal) was added as a new within-subjects factor, which was combined with probe valence (unpleasant vs. pleasant), and prime-probe congruence (congruent vs. neutral vs. incongruent), and the betweensubjects SOA factor (300 vs. $800 \mathrm{~ms} ; 24$ subjects at each level). At each SOA, for the 32 pleasant-people probes, each participant was presented with a different combination of 8 pleasant-people primes, 8 unpleasant-people primes, 8 pleasant-animal primes, and 8 unpleasant-animal primes; the same applied to the 32 unpleasant-people probes.

\section{Results and Discussion}

The 2 (prime category) $\times 2$ (valence of probe) $\times 2$ (prime-probe congruence) $\times 2$ (SOA) ANOVA revealed only a strong effect of congruence on correct-response times, 


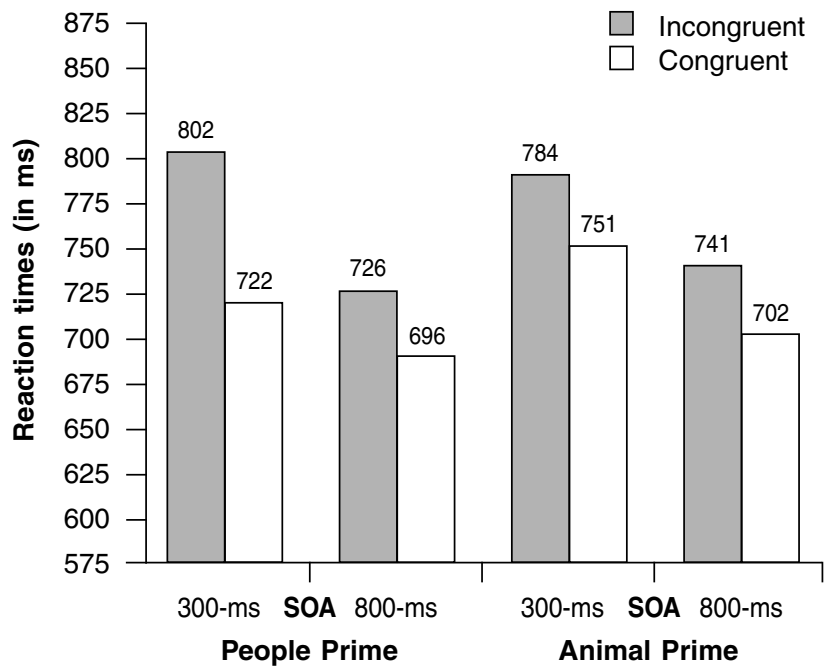

Figure 2. Mean reaction times as a function of prime-probe affective congruence, category of prime (people or animals; the probe always depicted people), and SOA (Experiment 2).

$F(1,46)=17.15, p<.0001, \eta_{\mathrm{p}}^{2}=.27$, with faster responses for congruent $(M=718 \mathrm{~ms} ; S D=174)$ than for incongruent $(M=763 \mathrm{~ms} ; S D=181)$ probes. That affective priming was reliable both within the same category and across categories was confirmed by significant effects of congruence for the person-prime/person-probe condition, $F(1,46)=10.57, p$ $<.01, \eta_{\mathrm{p}}{ }^{2}=.19$, and for the animal-prime/person-probe condition, $F(1,46)=4.99, p<.05, \eta_{\mathrm{p}}{ }^{2}=.10$, separately (see mean scores in Figure 2).

Although the time course of affective priming was not of specific interest in the current study, this topic has been relevant in prior research. To examine this issue, we combined the data from Experiments 1 and 2 for those conditions that were comparable (i.e., congruent and incongruent conditions in which people scenes were depicted), in a 2 (valence of probe $) \times 2$ (prime-probe congruence $) \times 2(\mathrm{SOA}) \times 2$

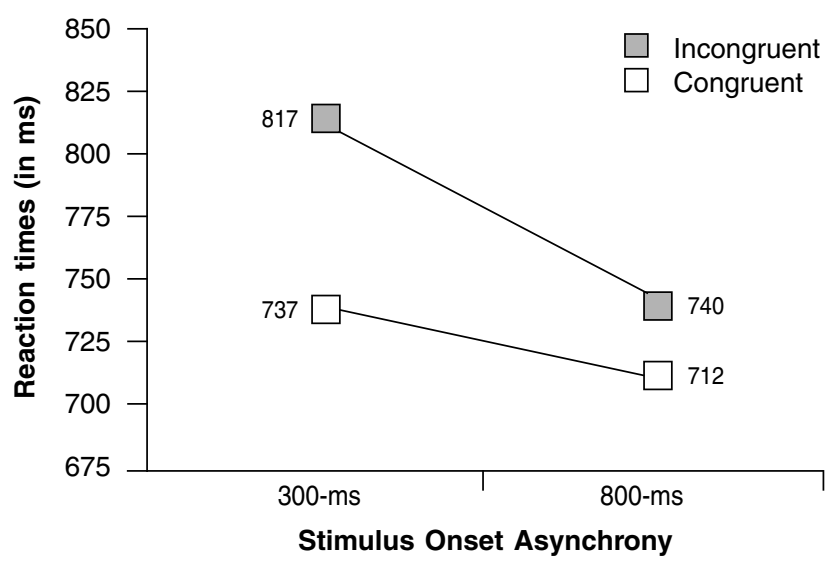

Figure 3. Mean reaction times for pictures portraying people scenes across Experiments 1 and 2, as a function of prime-probe affective congruence and SOA.
(Experiment). In addition to a significant effect of congruence, $F(1,92)=21.90, p<.0001, \eta_{\mathrm{p}}{ }^{2}=.19$, a congruence by SOA interaction emerged, $F(1,92)=4.98, p<.05, \eta_{\mathrm{p}}{ }^{2}=$ .05 (see Figure 3 ). This interaction was decomposed by means of a posteriori contrasts aimed at comparing the congruent and the incongruent probes for each SOA condition. Type I error was controlled for multiple comparisons (and it was set at .025, for two comparisons). In the 300-ms SOA condition, congruent probes were responded to faster than incongruent probes, $t(47)=4.30, p<.001$. In contrast, in the 800-ms SOA condition, differences did not reach the statistical significance level, $t(47)=2.12, p=.039, n s$. Accordingly, the interaction comes from the fact that there was significant facilitation for congruent probes only at the shortest SOA, which suggests that the affective priming effect is short-lived (see the General Discussion).

The specific finding of Experiment 2 indicated that there was generalization of priming across different semantic categories (people and animals). Furthermore, affective priming was not enhanced by category relatedness, as there was no interaction. This implies that the underlying affective content (beyond differences in semantic category) was extracted from the prime and then influenced the processing of the probe. In contrast, with narrow semantic categories (i.e., types of animals), Storbeck and Robinson (2004) found category priming effects (i.e., facilitation or interference as a function of category match or mismatch between prime and probe, regardless of prime-probe affective matching), but not affective priming. It is, however, possible that participants in the Storbeck and Robinson study were biased towards using semantic categorization in preference to affective processing due to their categories being narrow and specific (dogs, rabbits, snakes, and spiders), and therefore very salient and easy to be used as processing guides. If so, affective processing might be overridden when there are very salient cues (such as perceptual features associated with specific object categories) that make the stimuli clearly similar or different in specific nonemotional information, on the basis of which individuals can make discrimination and decisions easily. With broader semantic categories and perceptual variability than Storbeck and Robinson, we have found affective priming. Our results are consistent with those of Carroll and Young (2005; Experiment 2), who found affective priming from scenes of people and animals, as primes, to human emotional facial expressions, as probes, although category was not systematically manipulated in their study.

\section{General Discussion}

A general finding in these experiments revealed affective priming for emotional visual scenes: There were shorter latencies for probes when these were congruent in affective valence with a prime than when they were incongruent. Of special importance, there were two major findings related 
to the aims of this study, and one additional finding regarding the time course of affective priming. First, affective priming occurred even when the primes and the probes were very different in physical appearance, although the effect was enhanced as a function of prime-probe physical similarity (identical vs. reversed vs. different). Second, affective priming was reliable not only within the same semantic category, but also across different object categories (people vs. animals). And, third, affective priming emerged early (300 ms after the prime onset) and decreased over time (800 $\mathrm{ms}$ ), although this was reflected in shorter response latencies for incongruent probes rather than in changes for the congruent probes.

Is affective content extracted from the prime, and what kind of representation is responsible for the affective priming effect? Presumably, a meaningful impression is obtained very quickly from the prime, involving information about the emotional valence of the stimulus as good or bad. Affective priming occurred even when there were considerable differences in physical appearance and also differences in semantic category between the prime and the probe. This suggests that the priming effect was not produced simply by perceptual or semantic relatedness. Rather, some kind of nonperceptual and nonsemantic information must have also been obtained from the prime, which then speeded up the identification of the probe when it was of the same emotional valence, in comparison with when it was of different valence, regardless of physical and category differences.

The hypothesis that such a nonperceptual affective representation is responsible for affective priming is also supported by prior findings that have shown transfer from primes to probes of a different nature. Thus, affective priming has been found for pictures as primes and written or spoken words as probes (hence, physically different), which were, otherwise, congruent or incongruent in emotional valence (Banse, 2001; Carroll \& Young, 2005; Hermans et al., 2005; Hermans, Spruyt, De Houwer, et al., 2003; Hermans, Spruyt, \& Eelen, 2003; Hermans et al., 2002; Korpela et al., 2002; Spruyt et al., 2002). This does not deny the fact that some perceptual analysis is required and that perceptual similarity enhances affective priming. Rather, this generalization of priming across different sensory modalities and cognitive representation formats is consistent with the idea that the underlying affective content is processed and responsible for the priming effects.

The hypothesis that affective processing is not semantic either, or does not require semantic analysis, probably depends on how semantic content is defined. The affective representation is meaningful in that it involves evaluation of stimuli as positive or negative. However, it is not semantic in a more strict sense, such as category identification, which requires more refined analysis of specific information of stimuli. The fact that Storbeck and Robinson (2004) found category priming, but not affective priming, led these authors to conclude that semantic analysis occurs before (and is probably necessary for) affective evaluation. We have already argued that this category preference was probably biased by the use of very specific categories, with very salient perceptual cues to be discriminated. Consistent with this view is the fact that Storbeck and Robinson did find affective priming in their Experiment 3 (with words as stimuli, rather than pictures), when all stimuli came from a single semantic category. These authors then admitted that affective priming may be more likely when semantic variations are minimal.

The time course of affective priming with pictures is not directly relevant to the specific aims of this study, although our findings add to prior research in two respects. First, the current study has shown that affective processing is activated early and quickly (300-ms SOA and a 150 -ms prime display) the first (and only) time that the stimuli are presented. This confirms that the affective priming effects found in prior studies that used similar short SOAs and prime displaysalbeit repeated presentations of stimuli across trials-(Hermans et al., 1994; Hermans, Spruyt, \& Eelen, 2003; Hietanen \& Korpela, 2004; Korpela et al., 2002) reflected a genuine fastactivated process, not contaminated by pre-exposure. This is precisely what can be expected if affective processing is automatic (see Bargh, 1994). Second, some authors have proposed that the activation of affective content is short-lived, as priming occurs at short SOAs (300 ms or less) and disappears at longer SOAs (1,000 ms; Hermans et al., 1994; Hermans, Spruyt \& Eelen, 2003). However, affective priming has sometimes been detected at 1,000- and 1,200-ms SOAs (Hietanen \& Korpela, 2004; Korpela et al., 2002), and 750and 2,000-ms SOAs (Carroll \& Young, 2005). The findings from the current study support the view that affective priming is greatest at short delays (300-ms SOA), and declines or disappears at longer delays (800-ms SOA).

In conclusion, there is early processing of the affective content of pictorial stimuli that portray pleasant or unpleasant scenes. Discrimination between scenes occurs as a function of their differences in affective content, beyond and above differences in perceptual characteristics and semantic categories. Nevertheless, physical similarity facilitates processing of affective content, whereas category relatedness does not. Our data demonstrate that affective priming occurs early and despite variations in perceptual and semantic differences between a prime and a probe. This implies that affective processing can develop in parallel to detailed perceptual analysis and refined semantic analysis of the prime stimulus, to some extent. This does not imply, however, that affective processing precedes (or starts before) cognitive processing. The fact that physical prime-probe similarity speeds up affective priming suggests that some prior perceptual and semantic information (although not necessarily category information) must be obtained prior to initiating affective assessment. This is consistent with Storbeck et al.'s (in press) proposal that the features of objects must be integrated and that these must be identified prior to affective analysis. 


\section{References}

Banse, R. (2001). Affective priming with liked and disliked persons: Prime visibility determines congruency and incongruency effects. Cognition and Emotion, 15, 501-520.

Bargh, J.A. (1994). The four horsemen of automaticity: Awareness, intention, efficiency, and control in social cognition. In R.S. Wyer \& T.K. Srull (Eds.), Handbook of social cognition: Vol. 1. Basic processes (pp. 1-40). Hillsdale, NJ: Erbaum.

Bargh, J.A. (1997). The automaticity of everyday life. In R.S. Wyer (Ed.), The automaticity of everyday life: Advances in social cognition, Vol. 10 (pp. 1-61). Mahwah, NJ: Erbaum.

Carroll, N.C., \& Young, A.W. (2005). Priming of emotion recognition. The Quarterly Journal of Experimental Psychology, 58A, 1173-1197.

Cave, K., \& Batty, M. (in press). From searching for features to searching for threat: Drawing the boundary between preattentive and attentive vision. Visual Cognition.

Center for the Study of Emotion and Attention [CSEA-NIMH] (1999). The International Affective Picture System: Digitized photographs. Gainesville, FL: The Center for Research in Psychophysiology, University of Florida.

Fazio, R.H. (2001). On the activation of associated evaluations: An overview. Cognition and Emotion, 15, 115-141.

Giner-Sorolla, R., García, M.T., \& Bargh, J.A. (1999). The automatic evaluation of pictures. Social Cognition, 17, 76-96.

Hermans, D., Baeyens, F., Lamote, S., Spruyt, A., \& Eelen, P. (2005). Affective priming as an indirect measure of food preferences acquired through odor conditioning. Experimental Psychology, 52, 180-186.

Hermans, D., De Houwer, J., \& Eelen, P. (1994). The affective priming effect: Automatic activation of evaluative information in memory. Cognition and Emotion, 8, 515-533.

Hermans, D., de Houwer, J., \& Eelen, P. (2001). A time course analysis of the affective priming effect. Cognition and Emotion, $15,143-165$.

Hermans, D., \& Spruyt, A., De Houwer, J., \& Eelen, P. (2003). Affective priming with subliminally presented pictures. Canadian Journal of Experimental Psychology, 57, 97-114.

Hermans, D., Spruyt, A., \& Eelen, P. (2003). Automatic affective priming of recently acquired stimulus valence: Priming at SOA 300 but not at SOA 1000. Cognition and Emotion, 17, 83-99.

Hermans, D., Vansteenwegen, D., Crombez, G., Baeyens, F., \& Eelen, P. (2002). Expectancy learning and evaluative learning in human classical conditioning: Affective priming as an indirect and unobtrusive measure of conditioned stimulus valence. Behaviour Research and Therapy, 40, 217-234.

Hietanen, J.K., \& Korpela, K.M. (2004). Do both negative and positive environmental scenes elicit rapid affective processing? Environment and Behavior, 36, 558- 577.
Klauer, K.C., \& Musch, J. (2003). Affective priming. Findings and theories. In J. Musch \& K.C. Klauer (Eds.), The psychology of evaluation: Affective processes in cognition and emotion (pp. 7-49). Mahwah, NJ: Erlbaum.

Korpela, K.M., Klemettilä, T., \& Hietanen, J.K. (2002). Evidence for rapid affective evaluation of environmental scenes. Environment and Behavior, 34, 634-650.

Moltó, J., Montañés, S., Poy, R., Segarra, P., Pastor, M. C., Tormo, M.P., Ramírez, I., Hernández, M.A., Sánchez, M., Fernández, M.C., \& Vila, J. (1999). Un nuevo método para el estudio experimental de las emociones: El International Affective Picture System (IAPS). Adaptación española. Revista de Psicología General y Aplicada, 52, 55- 87.

Neely, J.H. (1991). Semantic priming effects in visual word recognition: A selective review of current findings and theories. In D. Besner \& G.W. Humphreys (Eds.), Basic processes in reading: Visual word recognition (pp. 264-336). Hillsdale, NJ: Erlbaum.

Rayner, K. (1998). Eye movements in reading and information processing: 20 years of research. Psychological Bulletin, 124, 372-422.

Schneider, W., Eschman, A., \& Zuccolotto, A. (2002). E-Prime user's guide. Pittsburgh, PA: Psychology Software Tools, Inc.

Spruyt, A., Hermans, D., De Houwer, J., \& Eelen, P. (2002). On the nature of the affective priming effect: Affective priming of naming responses. Social Cognition, 20, 227-256.

Spruyt, A., Hermans, D., De Houwer, J., \& Eelen, P. (2004). Automatic non-associative semantic priming: Episodic affective priming of naming responses. Acta Psychologica, 116, 39-54.

Storbeck, J., \& Robinson, M.D. (2004). Preferences and inferences in encoding of visual objects: A systematic comparison of semantic and affective priming. Personality and Social Psychology Bulletin, 30, 81-93.

Storbeck, J., Robinson, M.D., \& McCourt, M.E. (in press). Semantic processing precedes affect retrieval: The neurological case for cognitive primacy in visual processing. Review of General Psychology.

Vila, J., Sánchez, M., Ramírez, I., Fernández, M.C., Cobos, P., Rodríguez, S., Muñoz, M.A., Tormo, M.P., Herrero, M., Segarra, P., Pastor, M.C., Montañés, S., Poy, R., \& Moltó, J. (2001). El Sistema Internacional de Imágenes Afectivas (IAPS): Adaptación española. Segunda parte. Revista de Psicología General y Aplicada, 54, 635-657.

Zajonc, R. (2000). Feeling and thinking: Closing the debate over the independence of affect. In J.P. Forgas (Ed.), Feeling and thinking: The role of affect in social cognition. Studies in emotion and social interaction, Vol. 2. (pp. 31-58). New York: Cambridge University Press.

Received November, 8, 2005 Review received February 13, 2006 Accepted February 21, 2006 


\section{Appendix}

IAPS Number of Pictures Used as Positive and Negative Primes and Probes in Experiments 1 and 2.

Positive (People): 2000, 2040, 2057, 2058, 2070, 2092, 2160, 2165, 2311, 2332, 2340, 2341, 2352, 2360, 2395, 2540, 2550, 4574, 4599, 4624, 4641, 4643, 4653, 4660, 4680, 4687, 4694, 4700, 7325, 8461, 8490, 8499.

Positive (Animals): 1440, 1441, 1463, 1710, 1750, 1920, pa9 (non-IAPS), pa10 (non-IAPS).

Negative (People): 2120, 2683, 2691, 2703, 2799, 2800, 2900, 3022, 3030, 3180, 3181, 3350, 3530, 3550, 6250, 6313, 6510, 6550, 6560, 8231, 9040, 9230, 9250, 9253, 9254, 9410, 9421, 9429, 9440, 9490, 9594, 9921.

Negative (Animals): 1050, 1205, 1300, 1525, 1726, 1930, na2 (non-IAPS), na9 (non-IAPS). 